Opinions...

\section{Let's End the Double Standard for Natural versus Manufactured Chemicals*}

\section{J. L. Mattsson}

Health and Environmental Sciences, The Dow Chemical Co.

\section{Bias begets error in public policy}

There are no pre-determined differences between natural and manufactured ('synthetic') chemicals. Culturally, however, we have a bias that natural is good, and this bias can lead to errors in public policy and health protection. We know that natural chemicals are mutagenic, estrogenic, hepatotoxic, carcinogenic, neurotoxic, developmentally toxic, and so on ${ }^{1,2,6,7,12,14,18)}$. Obviously, chemicals are active due to their structure and dose, and not because they are synthesized by plants or insects, or synthesized by humans in laboratories and factories. Although toxicologists and other health professionals know that both natural and manufactured chemicals can be toxic, we behave as if a fundamental toxicologic difference exists. We have a bias against manufactured chemicals that is reflected in differences in educational content at universities, the content of toxicology text books, a bias in government funding of research, and a very different approach to regulation of exposure depending on source.

\section{The concept of natural versus synthetic is, itself, an error}

The first error in our thinking is reflected in the common differentiation of natural versus synthetic. A statement attributed to A. Einstein is more to the point : "If it is, it is natural." Because chemicals are synthesized by humans does not make them unnatural ; nature uses heat, enzymes, and all natural substrates to make chemicals. Humans use the same processes.

In addition to being conceptually wrong, to differentiate between natural and synthetic chemicals is misleading. It is implied that natural chemicals are not influenced by human activity, and that synthetic chemicals are solely the product of human enterprise. Humans, however, act through natural sys-

Received Nov 9, 1995; Accepted Dec 6, 1995

Correspondence to : J. L. Mattsson, The Dow Chemical Company, Health and Environmental Sciences, 1803 Building, Washington Street, Midland, MI 48674, USA

*Presented as Con argument in a debate, "Exposure To Syrthetic Chemicals Is More Hazardous Than Exposure To Natural Chemicals." International Congress of Toxicology-VII, July 2-6, 1995, Seattle, Washington, USA tems. Humans select certain plants for agriculture (edible but pest resistant), hybridize plants, and use genetic engineering to alter the gene expression of plants. Both by selection and manipulation, the plants are no longer completely natural. Humans also mimic nature. For example, organohalides such as methyl chloride, chloroform, dichlorophenol (and many others) are synthesized by nature ${ }^{10)}$ and also by humans. Over 1500 'natural' chlorinated molecules are known, synthesized by bacteria, fungi, plants and insects. Marine life is the major source of organohalogens, and many of these organohalogens are well known to toxicologists. Another example is antibiotics, which are found in nature, but are selected and altered by humans to improve efficacy and productivity. Where, really, does nature leave off and human enterprise begin?

Although in the human environment the differences between 'natural' and 'synthetic' chemicals is blurred, this distinction will be retained for the remaining paragraphs (but in quotation marks to identify the weakness of the distinction).

\section{Most exposure to toxicants comes from 'natural' sources}

Whether or not people are exposed to low or high levels of 'synthetic' chemicals, their exposure to 'natural' toxicants is high. Plants contain high levels of 'natural' toxicants'). Because plants cannot run from or fight those organisms that eat them, they have evolved special defenses. Some grow spines, many have husks and rinds, and all use chemical defenses. In addition, plants also carry fungal toxins as contaminants. Although unlikely to protect plants (due to inefficiency from delayed occurrence), a high percentage of 'natural' toxicants are carcinogens ${ }^{1,17)}$. Carcinogenicity may be an incidental property of 'natural' toxicants, but cancer is of considerable concern to humans.

Of more immediate value to the plant, some plant toxicants are enormously potent. For example, the root of water hemlock is like a parsnip and tastes sweet, but contains cicutoxin. As little as one or two bites of the root can kill with respiratory distress and unrelenting convulsions. Children have died just by carrying a root in their hands. This member of the parsnip and carrot family is far too toxic to be used as food. Fortunately, the toxic content of some plants is low enough that we are not acutely poisoned and can use them for food. But, even food plants contain high levels of toxicants. For example, Morris and Lee (1984) advised that women who are pregnant, or likely to become pregnant, to avoid any slightly green or damaged potatoes because of higher than usual glycoalkaloid con- 
tent. The problem for humans is that the toxic content of all plants has to be high enough to allow plants to survive in a very aggressive world of plant viruses, bacteria, fungi, insects and larger predatory animals like rabbits, cows and people.

Plants normally respond to stress by increasing their toxicant content; thus, the level of 'natural' toxicants can be quite high in damaged crops ${ }^{11,15)}$. Stressors are weather, physical injury, and attack from microorganisms, insects, and larger predators. Foods that are 'safe' when unstressed can become acutely toxic when stressed. It needs to be emphasized that foods are considered safe only in the context of acute toxicity; there has been little study of the long-term consequences of exposure to 'natural' chemicals. It should be of even greater concern to evaluate the effects of long-term exposure of infant and young humans to 'natural' toxicants.

\section{Co-evolution is a weak argument for safety of 'natural' toxicants}

Many people argue that humans are protected by evolution against 'natural' chemicals. For example, there are many enzymes in the liver that seem to have no function other than to detoxify dietary chemicals $^{9)}$ (many P450 enzymes). Although correct to a degree, the co-evolutionary argument is defidcient from several perspectives. To begin with, we co-evolved in a general sense with everything that grows, plant or animal. Yet, there are very few plants that people can eat, and there are many plants and animals that are very poisonous to humans. Also, species evolve in ecologic niches or geographic zones. Plant species are different from one place to another, so people evolving in one location that migrate to another did not co-evolve with their new environment and would, therefore, be sensitive to intoxication.

Another problem with the co-evolution argument is that evolution takes time. Most plants and microorganisms have a much shorter reproductive cycle than humans, and thereby gain evolutionary advantage over humans. As humans modernized and became more agricultural, new crop species and new cultivars were developed at a faster pace than human evolution could possibly follow. Today we have genetic engineering, where new foods and new crop chemistry can be developed very quickly, and over a short period of time we can be faced by yet another 'natural' chemical ${ }^{5,8}$. Thus, in spite of our wonderful ability to detoxify chemicals in our livers and other organs, the 'natural' world is a very dangerous place and errors in public policy could make it yet more dangerous.

\section{'Synthetic' chemicals can reduce risk}

It has been argued that 'natural' chemicals are unavoidable and that 'synthetic' chemicals only add to our toxic burden. Fortunately, this is untrue. Examples of how 'synthetic' chemicals are used to reduce risk are endless, and therefore only a few examples will be given. In the physical domain, modern material science has improved building construction, housing, clothing, and other items to protect us from physical agents such as weather, earth quake, sun exposure and physical injury. Polymers are used to make automobile airbags and energy absorbing surfaces to protect us from collision injury. 'Synthetic' chemicals are used to make filters to reduce our exposure to allergens. And so forth.

In the chemical domain, drugs are used to improve health in multitudes of ways and need no further discussion. Agricultural chemicals increase the quantity and quality of our food supply, an essential requirement for a healthy population. However, an unrecognized benefit of use of crop protection chemicals is a reduced net exposure to toxicants (an apparent contradiction). In addition to food crops acting as a source of fungal toxins ${ }^{3)}$, crops that are stressed by competition from weeds, and from attack from infections and bugs, have increased levels of 'natural' pesticides, 11,13,15). Crops protected from stress have smaller amounts of 'natural' pesticide. These 'natural' pesticides commonly are mutagenic and carcinogenic, as well as having the capability of inducing a large variety of other types of toxicities, ${ }^{1,6,7)}$. Manufactured crop-protection chemicals are screened for mutagenicity, carcinogenicity, organ toxicity and the like, and exposure is rigorously regulated. Hence, proper use of cropprotection chemicals can cause a net reduction in toxicant exposure by reducing exposure to the potentially more hazardous and abundant 'natural' pesticides.

The point is not that 'synthetic' chemicals should be preferred to 'natural' sources, because this is not so. The point is to use the chemical that best meets our needs and is safest to use. Sometimes the source will be 'natural', and at other times the source will be 'synthetic'. In all cases the chemical should be properly evaluated for safety.

\section{Allow no double standards}

Unfortunately, strong double standards exist in the testing and regulation of toxicants to which humans are exposed. So called 'natural' chemicals are tested to a much lesser degree than manufactured chemicals, and some countries have policies that favor reduced test requirements of 'natural' chemicals. Herein lies the problem; different test 
strategies for 'natural' and 'synthetic' chemicals lead to different data bases. People commonly worry more about defined hazards than about data gaps, especially when the data gaps are on 'natural' chemicals for which there is a bias toward lack of concern. Decisions, then, are based on qualitatively and quantitatively different data sets in a social environment that favors 'natural' chemicals. Serious errors in decision making can occur. Obviously, this double standard has no scientific basis and should be changed. We have learned a lot in the last two or three decades about toxicity testing, and today we are well aware that 'natural' chemicals are plentiful and toxic. We need to overcome our inertia and use contemporary toxicology skills to design a single strategy to efficiently screen, prioritize, and test all sources of potentially harmful chemicals. We owe the public our best effort, and no double standards should be allowed.

\section{References}

1) Ames, BN. Dietary carcinogens and anticarcinogens. Science $221: 1256-1264,1983$.

2) Ames, BN, Gold, LS. The causes and prevention of cancer: the role of environment. In: Bailey, R, ed. The true state of the planet. New York: Free Press, 1995 : 142-175.

3) Bach, PH, Bartsch, H. Fungal toxins and health. TiPs $1993 ; 14: 424-425$.

4) Birch, ANE, Griffiths, DW, Hopkins, RJ, Smith, WHM, McKinlay, RG. Glucosinolate responses of Swede, kale, forage and oilseed rape to root damage by turnip root fly (Delia floralis) larvae. J Sci Food Agric 1992; 60: 1-9.

5) Clayson, DB. Food safety: Are human activities really worse than nature's? Reg Toxicol Pharmacol $1993 ; 17: 145-156$.

6) Cheeke, PR. Toxicants of Plant Origin. Vol. I, Alkaloids; Vol. II, Glycosides; Vol. III, Proteins and Amino Acids; Vol. IV, Phenolics. CRC Press, Boca Raton, 1989
7) D'Mello, JPF, Duffus, CM, and Duffis, JH. Toxic substances in crop plants. The Royal Society of Chemistry, Cambridge: Thomas Graham House, 1991.

8) Fenwick, GR, Johnson, IT, and Hedley, CL. Toxicity of disease-resistant plant strains. Trends Food Sci Technol 1990; July : 23-45.

9) Gonzalez, FJ, Gelboin, HV. Role of human cytochrome $\mathrm{P}-450$ s in risk assessment and susceptibility to environmentally based disease. J Toxicol Environ Health $1993 ; 40$ : 289-308.

10) Gribble, GW. Naturally occurring organohalogen compounds-a survey. J Natural Products $1992 ; 55$ : $1353-1395$.

11) Haard, NF, Salunkhe, DK. Stress metabolites in fruits and vegetables-introduction. J Food Prot $1979 ; 42: 495$.

12) Harborne, JB, Baxter, H. Phytochemical Dictionary : A Handbook of Bioactive Compounds from Plants. London: Taylor and Francis, 1993.

13) Hlywka, JJ, Stephenson, GR, Sears, MK, Yada, RY. Effects of insect damage on glycoalkaloid content in potatoes (Solanum tuberosum). J Agricul Food Chem $1994 ; 42$ : 2545-2550.

14) Hopkins, J. The glycoalkaloids : naturally of interest (but a hot potato?). Food Chem Toxicol 1995; 33: 323-328.

15) Mongeau, R, Brassard, R, Cerkauskas, R, Chica, M, Lok, E, Nera, EA, Jee, P, McMullen, E, Clayson, DB. Effect of addition of dried healthy or diseased parsnip root tissue to a modified AIN-76A diet on cell proliferation and histopathology in the liver, oesophagus and forestomach of male Swiss Webster mice. Food Chem Toxicol 1994; 32 : 265-271.

16) Morris, SC, Lee, TH. The toxicity and teratogenicity of Solanaceae glycoalkaloids, particularly those of the potato (Solanum tuberosum): a review. Food Tech Australia $1984 ; 36: 118-124$.

17) Rosenkranz, HS, Klopman, G. Natural pesticides present in edible plants are predicted to be carcinogenic. Carcinogenesis $1990 ; 11: 349-353$.

18) Safe, SH. Environmental and dietary estrogens and human health: is there a problem? Environ Health Perspect 1995; 103: 346-351. 